\title{
Postoperative delirium in old patients with femoral neck fracture: a randomized intervention study
}

\author{
Maria Lundström¹, Birgitta Olofsson ${ }^{1,2}$, Michael Stenvall ${ }^{1}$, Stig Karlsson ${ }^{1}$, Lars Nyberg ${ }^{3}$, \\ Undis Englund ${ }^{1}$, Bengt Borssén ${ }^{4}$, Olle Svensson ${ }^{2}$, and Yngve Gustafson ${ }^{1}$ \\ ${ }^{1}$ Department of Community Medicine and Rehabilitation, Geriatric Medicine, Umeå University, Umeå, \\ ${ }^{2}$ Department of Surgical and Perioperative Science, Orthopedics, Umeå University, Umeå, ${ }^{3}$ Department of \\ Health Sciences, Luleå University of Technology, Luleå, ${ }^{4}$ Department of Orthopedics, Umeå University \\ Hospital, Umeå, Sweden
}

ABSTRACT. Background and aims: Delirium is a common postoperative complication in elderly patients which has a serious impact on outcome in terms of morbidity and costs. We examined whether a postoperative multi-factorial intervention program can reduce delirium and improve outcome in patients with femoral neck fractures. Methods: One hundred and ninety-nine patients, aged 70 years and over (mean age $\pm S D, 82 \pm 6,74 \%$ women), were randomly assigned to postoperative care in a specialized geriatric ward or a conventional orthopedic ward. The intervention consisted of staff education focusing on the assessment, prevention and treatment of delirium and associated complications. The staff worked as a team, applying comprehensive geriatric assessment, management and rehabilitation. Patients were assessed using the Mini Mental State Examination and the Organic Brain Syndrome Scale, and delirium was diagnosed according to DSM-IV criteria. Results: The number of days of postoperative delirium among intervention patients was fewer $(5.0 \pm 7.1$ days vs $10.2 \pm 13.3$ days, $p=0.009)$ compared with controls. A lower proportion of intervention patients were delirious postoperatively than controls (56/102, $54.9 \%$ vs 73/97, 75.3\%, $\mathrm{p}=0.003)$. Eighteen percent in the intervention ward and $52 \%$ of controls were delirious after the seventh postoperative day $(\mathrm{p}<0.001)$. Intervention patients suffered from fewer complications, such as decubitus ulcers, urinary tract infections, nutritional complications, sleeping problems and falls, than controls. Total postoperative hospitalization was shorter in the intervention ward (28. $0 \pm 17.9$ days vs $38.0 \pm 40.6$ days, $\mathrm{p}=0.028)$. Conclusions: Patients with postoperative delirium can be successfully treated, resulting in fewer days of delirium, fewer other complications, and shorter length of hospitalization.

(Aging Clin Exp Res 2007; 19: 178-186)

๑2007, Editrice Kurtis

\section{INTRODUCTION}

Delirium is a neuropsychiatric syndrome characterized by disturbed attention and cognition, with a fluctuating course and, by definition, it always has an underlying cause (1). Delirium prolongs hospital stays, reduces functional ability, increases mortality, and occurs in 38-61\% of older hip fracture patients (2-5). Although delirium is sometimes the cause of the fall that resulted in the hip fracture, most patients develop delirium as a result of medical complications during their hospital stay $(2,3,6)$.

Postoperative delirium has been reported as being precipitated by perioperative hypotension, hypoxemia and anaemia, and can be prevented and treated by avoiding or treating such conditions (2, 7-9). Stress caused by the injury, admission to hospital, and surgery itself also seem to contribute to delirium, probably mediated by hypercortisolism (10-12). The combination of hypercortisolism and factors threatening cerebral oxygen metabolism seems to be especially dangerous for the old, frail, hip fracture patient (11-14). Good nursing, reduction of stress by creating a safe and secure caring situation, and prevention of complications such as urinary retention, pain, malnutrition and constipation, seem to be prerequisites for the prevention and treatment of delirium $(8,15)$.

Intervention studies have shown that delirium after hip fracture surgery can be prevented and treated (7-9, 15-17). However, only two of these studies reported randomized controlled trials, and the effect of the multi-

Key words: Delirium, femoral neck fracture, geriatric team, intervention, RCT.

Correspondence: Maria Lundström, RN, PhD, Geriatric Medicine, Department of Community Medicine and Rehabilitation, Umeå University, SE-901 87 Umeå, Sweden.

E-mail: maria.lundstrom@germed.umu.se

Received April 5, 2006; accepted in revised form August 8, 2006. 
factorial prevention and treatment programs in these studies either did not remain significant after controlling for baseline differences (9) or the effect of delirium did not reach statistical significance (16). Non-randomized studies have indicated that the combination of both medical and nursing interventions seems to be a prerequisite for successful prevention and treatment of delirium $(8,18)$.

We therefore examined, in a randomized study, whether a postoperative multi-factorial intervention program, including comprehensive geriatric assessment, management and rehabilitation, can reduce delirium and improve outcome in patients with femoral neck fractures.

\section{METHODS}

\section{Study Population}

The present study included patients aged 70 years or older, consecutively admitted to the Orthopedic Department at the University Hospital in Umeå, Sweden, between May 2000 and December 2002, with femoral neck fracture. Exclusion criteria were: age under 70, severe rheumatoid arthritis, severe hip osteoarthritis, severe renal failure, pathological fracture, and patients who were bedridden before the fracture due to the operation methods that were planned to be used in the study.

\section{Study Procedure}

In the emergency room, patients were asked both in writing and orally if they were willing to participate in the study. In the case of patients with cognitive impairment, next-of-kin were also asked. Two hundred and fiftyeight patients met the inclusion criteria, but 59 patients declined or did not participate in the study for other reasons (Fig. 1).

These 59 patients tended to be more often admitted from their own house/apartment $(p=0.009)$ and were more likely to be males $(p=0.033)$, but there was no difference in age ( $p=0.354)$ compared with the 199 patients included. All patients received the same preoperative treatment in the orthopedic ward.

The Ethical Committee of the Faculty of Medicine at Umeå University approved the study (§ 00-137).

\section{Randomization}

Patients were randomized to postoperative care in a geriatric ward with a special intervention program or to conventional care in the orthopedic department, by sealed and opaque envelopes. Randomization was stratified according to the dislocation of the fracture, to have similar proportions of different surgery methods in both groups. All participants received their envelopes while in the emergency room, but they were not opened until immediately before surgery, to ensure similar preoperative treatment. The mean waiting time for operation was similar between the intervention (mean 24.5 hours) and control groups (mean 24.8 hours). A nurse on duty at the orthopedic department, who was not involved in the study, opened the envelopes. Depending on the degree of dislocation (19), patients were treated with two hook-pins (Swemac Orthopedica ${ }^{\circledR}$, Linköping, Sweden) (intervention group $n=38$, control group $n=31$ ) or with bipolar hemiarthroplasty (Link ${ }^{\circledR}$, Hamburg, Germany) (intervention group $n=57$, control group $n=54$ ). Basocervical fractures (intervention group $n=7$, control group $n=10$ ) received dynamic hip screws (DHS, Stratec Medical ${ }^{\circledR}$, Oberdorf, Switzerland). One patient in the control group had a resection of the femoral head, due to deterioration in medical status, and another control patient died before surgery. Most operations (174/198, 88\%) were performed under spinal anesthesia.

\section{Intervention}

Patients randomized to the intervention group were admitted to a 24-bed geriatric unit specializing in geriatric orthopedic patients. The staff worked as a team, applying comprehensive geriatric assessment, management and rehabilitation (Table 1) $(20,21)$. The staffing level at the intervention ward was 1.07 nurses/aids per bed.

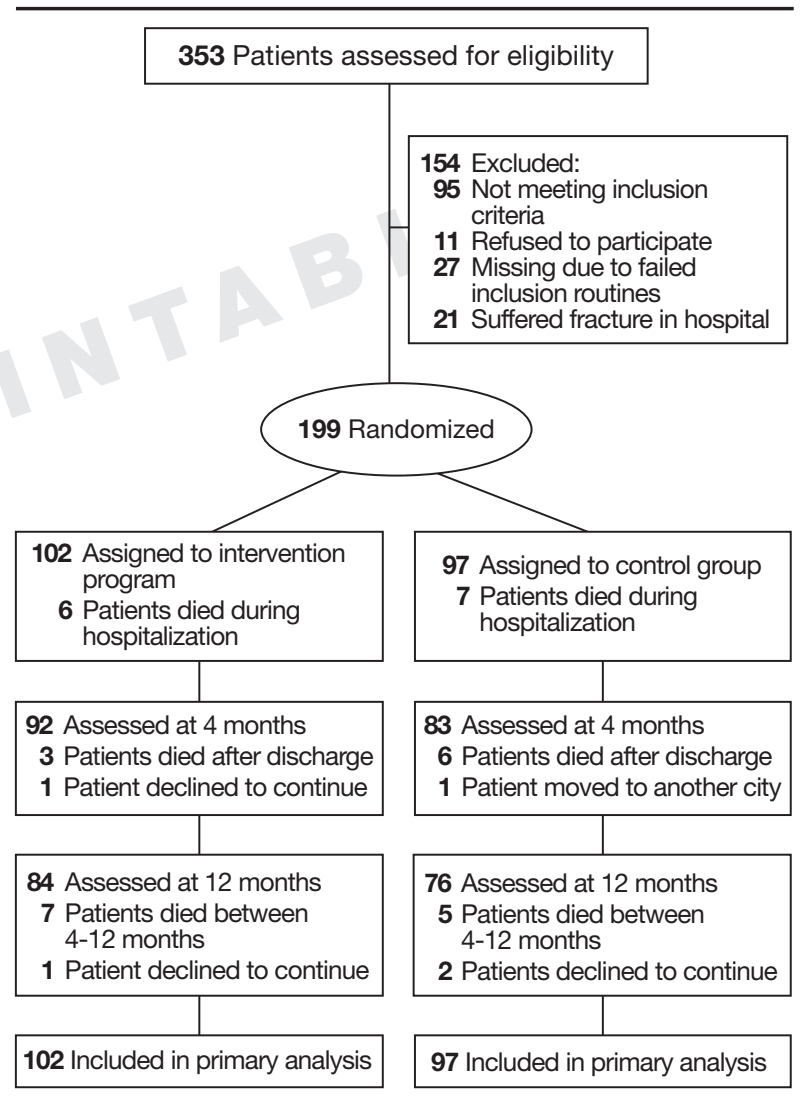

Fig. 1 - Flow chart for randomized trial. 


\section{Control Group}

The control group received postoperative care in the Orthopedic Department according to the usual postoperative care routines (Table 1). The staffing level in the orthopedic wards was 1.01 nurses/aids per bed. Patients who needed further in-hospital rehabilitation were admitted to a geriatric ward $(n=40)$ but not to the intervention ward. That geriatric ward had a staffing level of 1.07 nurses/aids per bed.

A similar proportion of other professionals worked in both control and intervention wards, but they had developed a plan, which included more teamwork, in the intervention ward.

The staff on the intervention ward was aware of the nature of the study, and those on the control ward knew that a new care program was being evaluated in the geriatric ward.

\section{Primary Outcome Measures}

Primary outcome measures were number of days of postoperative delirium. In addition all patients were observed every day pre- and postoperatively. All symptoms and signs of delirium and/or changes in patients' mental state were registered in the nurses' records (in both intervention and control groups) according to daily documentation, which is routinely performed at least three times a day. All patients were tested once between days 3-5 postoperatively with the Mini Mental State Examination (MMSE) (22), Organic Brain Syndrome Scale (OBS-Scale) (23) and Geriatric Depression Scale (GDS-15) $(24,25)$. The GDS-15 is reported to have high sensitivity and specificity regarding the diagnosis of depression (26). Two nurses were employed half-time in the study and were trained to carry out the assessments in the two

Table 1 - Main content of postoperative intervention program

\begin{tabular}{|c|c|}
\hline Staff education & $\begin{array}{l}\text { - A four-day course in caring, rehabilitation, teamwork and medical knowledge, including sessions about how to prevent } \\
\text { and treat various postoperative complications including postoperative delirium (risk factors, prevention and treatment). } \\
\text { The course also included sessions on osteoporosis, hip fractures, operation methods, anesthesia, postoperative care, } \\
\text { pain, sleep and sleep apnea, individual care planning and nutrition. } \\
\text { - The staff in the control group did not receive any specific education before or during the study. }\end{array}$ \\
\hline Teamwork & $\begin{array}{l}\text { - Team included Registered Nurses (RN), Licensed Practical Nurses (LPN), Registered Physiotherapists (PT), Registered } \\
\text { Occupational Therapists (OT), a dietician and geriatricians. } \\
\text { - There was close co-operation between orthopedic surgeons and geriatricians in the medical care of patients. } \\
\text { - The PT/OT also co-operated with colleagues working in community service, for further consultations after patients were } \\
\text { discharged from hospital. } \\
\text { - This was not performed consistently for control patients. }\end{array}$ \\
\hline $\begin{array}{l}\text { Individual care } \\
\text { planning }\end{array}$ & $\begin{array}{l}\text { - To be able to start the individual care planning, all team members (except the dietician) assessed each patient usually } \\
\text { within } 24 \text { hours, after admission. } \\
\text { - Team planning of patients' individual rehabilitation process and goals twice a week during the whole rehabilitation period. } \\
\text { - This was not performed consistently for control patients. }\end{array}$ \\
\hline Delirium & $\begin{array}{l}\text { - Active prevention, detection and treatment of delirium. } \\
\text { - Assessment of all patients with delirium for precipitating factors. } \\
\text { - This was not performed consistently for control patients. }\end{array}$ \\
\hline
\end{tabular}

\section{Prevention and treatment of complications}

Infection - Systematical screening for urinary tract infections, and treated when indicated.

- Other infections were treated on demand.

- This was not performed consistently for control patients.

Anemia $\quad$ Blood transfusions if B-hemoglobin, $\mathrm{g} / \mathrm{l}<100$.

- Blood transfusions if B-hemoglobin $\mathrm{g} / \mathrm{l}<110$ for those at risk of delirium or those already delirious.

- This was not performed consistently for control patients.

Embolism - Anti-thrombosis treatment during first two postoperative weeks.

- Anti-thrombosis stockings were given to all patients.

- Control patients received similar treatment.

\begin{tabular}{ll}
\hline Bowel/bladder & - If a urinary catheter was used during surgery, it was discontinued within 24 hours postoperatively. \\
function & - Systematic regular screening for urinary retention. \\
& - If urinary retention was detected, an intermittent catheter was preferably used. \\
& - Active prevention and treatment of constipation. \\
& - This was not performed consistently for control patients.
\end{tabular}


Table 1 - Main content of postoperative intervention program. (continued)

\begin{tabular}{|c|c|}
\hline $\begin{array}{l}\text { Sleep, } \\
\text { sleep apnea }\end{array}$ & $\begin{array}{l}\text { - The reason was always investigated and the cause was then treated, if patients had sleeping problems. } \\
\text { - This was not performed consistently for control patients. }\end{array}$ \\
\hline Decubitus ulcers & $\begin{array}{l}\text { - Decubitus ulcers were systematically prevented and treated. } \\
\text { - Control patients received similar treatment. }\end{array}$ \\
\hline Pain & $\begin{array}{l}\text { - Prevention and treatment of postoperative pain. All patients received: Paracetamol - max } 4 \mathrm{gr} / \text { day, and Tramadol hydrocloride } \\
\text { - max } 200 \mathrm{mg} / \text { day, or Dextropropoxifennapsylat - max } 200 \mathrm{mg} / \text { day, or Codeinfosfathemihydrat - max } 180 \mathrm{mg} / \mathrm{day} \text {. } \\
\text { - In cases of severe pain, Ketobemidonhydrocloride } 2.5-5 \mathrm{mg} \text {, or Morphinehydrocloride } 2.5-5 \mathrm{mg} \text { when necessary. } \\
\text { - Delirious patients were usually assessed for the underlying causes of their pain. } \\
\text { - Similar routines for pain treatment were used in the control group. } \\
\text { - Patients with delirium in the control group were often treated with Ketobemidonhydrocloride, without assessment } \\
\text { of underlying causes. }\end{array}$ \\
\hline Saturation & $\begin{array}{l}\text { - Oxygen-enriched air during the first postoperative day, and longer if necessary, until measured oxygen saturation was stable. } \\
\text { - This was not performed consistently for control patients. }\end{array}$ \\
\hline Body temperature & $\begin{array}{l}\text { - Body temperature measured during the first three postoperative days, and longer if indicated. } \\
\text { - Similar routines were performed in the control group. }\end{array}$ \\
\hline Blood pressure & $\begin{array}{l}\text { - Blood pressure measured the first two postoperative days, and longer if indicated. } \\
\text { - Only performed on demand in the control group. }\end{array}$ \\
\hline Nutrition & $\begin{array}{l}\text { - Food and liquid intakes were systematically recorded four days postoperatively. } \\
\text { - Protein-enriched meals were served to all patients during the first four postoperative days, and longer if necessary. } \\
\text { - Nutritional and protein drinks were served twice a day throughout hospitalization. } \\
\text { - Consultation with the dietician when necessary. } \\
\text { - This was not performed consistently for control patients. } \\
\text { - No dietician was available for the control group. }\end{array}$ \\
\hline Rehabilitation & $\begin{array}{l}\text { - Mobilization within the first } 24 \text { postoperative hours. } \\
\text { - Training took place every day assisted by a PT, OT, and caring staff. } \\
\text { - Training was based on functional retraining, with special focus on fall risk factors. } \\
\text { - Patients were always encouraged to do as much as they could by themselves before they were helped. } \\
\text { - This was not performed consistently for control patients. }\end{array}$ \\
\hline Secondary prever & $\begin{array}{l}\text { ion of falls and fractures. Osteoporosis prophylaxis } \\
\text { - Investigation regarding how and why patients had sustained hip fracture. } \\
\text { - Actions to prevent new falls and fractures were implemented. } \\
\text { - Calcium and Vitamin D to all intervention patients, and other pharmacological treatment if indicated. } \\
\text { - This was not performed consistently for control patients. }\end{array}$ \\
\hline
\end{tabular}

wards. An occupational therapist, a physiotherapist and physicians were also employed to assess the patients in the project.

The MMSE was used to assess patients' cognitive status, and has scores from 0 to 30 points. To screen for delirium, the modified OBS scale was used, which consists of two main parts: the disorientation subscale, a questionnaire containing 12 items; and the confusion subscale, an observation schedule covering 21 clinical features. The disorientation subscale measures patients' orientation to time, place, and their own identity, with a maximum score of 36 (the higher the score, the worse the result). The confusion subscale describes various cognitive, perceptual, emotional and personality changes, and fluctuations in clinical state, and is based on observation and interviews with the patient as well as interviews with caregivers. The OBS-scale has been compared with other assessment scales and has proved to have good concurrent validity $(23,27)$. When compared with the Confusion Assessment Method (CAM), it showed $100 \%$ agreement regarding the diagnosis of delirium (28).

Symptoms and signs of delirium during the first eight postoperative hours were ascribed to the immediate effects of premedication and/or other anesthetic agents, and were not registered as delirium. Patients were registered as delirious on discharge if they had had any episodes of delirium in the last 24 hours of hospitalization. 
Depression before hospitalization was diagnosed after an evaluation of earlier diagnoses documented in the records, and current treatment with antidepressants. Depression during hospitalization was diagnosed if patients were currently being treated with antidepressants and if they were screened for depression using the GDS-15 in combination with depressive symptoms observed and registered with the OBS-Scale.

Medical and social data were collected from the patients, relatives, staff and medical records. Prefracture Personal Activities of Daily Living (P-ADL) were recorded according to Katz ADL-index (29).

A specialist in geriatric medicine, who was not working in either of the two wards and did not know to which group patients were randomized, analyzed all assessments and documentation, including all patients' medical and nursing records, to decide whether the patients met the DSM-IV criteria for delirium, dementia and depression (1). All assessments and documentation were analyzed after the study was finished. The first step of analysis was performed totally blind, when evaluating assessments performed by the study nurses. The second step was when all the documentation in the records was read and analyzed with regard to any signs or symptoms indicating delirium for each day. This was not possible to perform totally blind, but since the records of each day were used and included documentation from more than 6500 days, it was difficult for the geriatrician to know to which group the patients belonged.

\section{Secondary Outcome Measures}

Secondary outcome measures were complications during hospitalization, length of stay, and in-hospital and one-year mortality. All complications were systematically documented in the records. After four and twelve months, the study group visited and assessed all patients in the study.

\section{Statistical Methods}

The sample size was calculated to detect a $25 \%$ difference in number of days with delirium between intervention and control groups, at a significance level of 0.05. Univariate analyses using Student's t-test, Pearson's $\chi^{2}$ test and Fisher's Exact test were performed to describe group differences, and a $p$-value of $<0.05$ was regarded as statistically significant. Multivariate linear regression analyses were used to control for baseline differences $(p<0.150)$ associated with delirium and age and sex between controls and the intervention sample.

The analysis was based on the intention-to-treat principle, including all randomized patients.

\section{RESULTS}

The number of days with postoperative delirium among intervention patients were fewer $(5.0 \pm 7.1$ days us $10.2 \pm 13.3$ days, $p=0.009)$ compared with controls. A smaller proportion of the intervention patients were delirious postoperatively than controls $(56 / 102$, $54.9 \%$ us $73 / 97,75.3 \%, p=0.003$ ) and this was already seen from postoperative day 1 . The differences in postoperative delirium in the two groups remained significant each day for the first postoperative week $(p=0.001)$. A larger proportion of control patients were delirious on at least one occasion during hospitalization after day 7 ( $p=0.001$ ) (Fig. 2). Eighteen percent of intervention patients were delirious after the seventh postoperative day, compared with $52 \%$ of controls $(p<0.001)$. Twenty patients in the control ward were delirious or had had episodes of delirium on the day of discharge, in contrast with none from the intervention ward $(p<0.001)$.

There were some differences at baseline between the patients in the two wards (Table 2). More patients in the control group were depressed before the fracture (47.4\% vs $32.4 \%, p=0.031)$ and more were prescribed antidepressants ( $46.4 \%$ vs $28.4 \%, p=0.009)$, but equal GDS-scores were recorded in both groups during hospitalization (Table 3).

Among patients with postoperative delirium, the only significant differences at baseline were that a higher proportion of the control patients were prescribed antidepressants $(54.8 \%$ vs $35.7 \%, p=0.031)$ and they had had a previous wrist fracture $(25.0 \%$ vs $10.7 \%, p=0.040)$, compared with patients with postoperative delirium in the intervention group. There was no significant difference in the prevalence of preoperative delirium between the two groups, $21.8 \%$ of intervention patients and $30.9 \%$ of control patients were delirious preoperatively $(p=0.144)$.

Intervention patients suffered fewer complications during hospitalization (Table 3 ). Controls with postoperative delirium had more urinary infections $(60.3 \%$ vs $39.3 \%$, $p=0.018)$, more sleeping problems $(50.7 \%$ vs $28.6 \%$, $p=0.011)$, more falls $(34.3 \%$ vs $17.9 \%, p=0.034)$ and de-

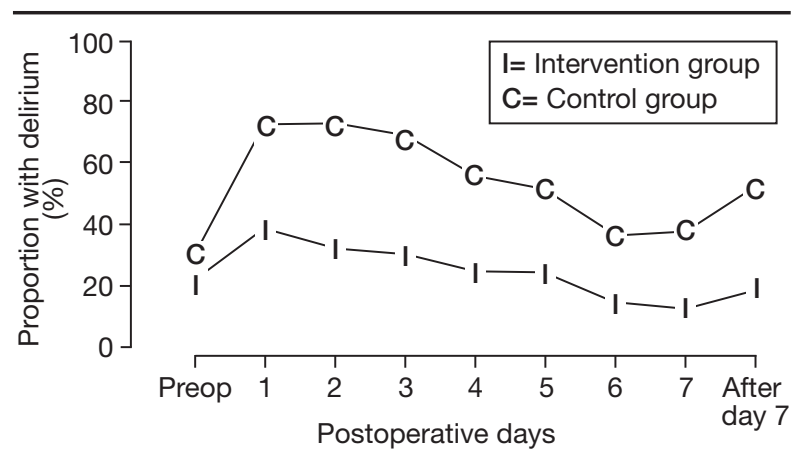

Fig. 2 - Line plot showing proportion of patients with delirium each day during hospitalization in intervention (I) us control groups (C). 
Table 2 - Characteristics and previous diagnoses and drugs on admission of patients in intervention group us control group.

\begin{tabular}{|c|c|c|c|}
\hline & $\begin{array}{c}\text { Intervention } \\
\text { group } \\
(\mathbf{n}=102)\end{array}$ & $\begin{array}{c}\text { Control } \\
\text { group } \\
(\mathbf{n}=97)\end{array}$ & \\
\hline Characteristics & n (\%) & n (\%) & p-value \\
\hline Male/female & $28 / 74$ & $23 / 74$ & 0.546 \\
\hline Age, mean $\pm \mathrm{SD}$ & $82.3 \pm 6.6$ & $82.0 \pm 5.6$ & 0.724 \\
\hline $\begin{array}{l}\text { Admitted from own } \\
\text { house/apartment }\end{array}$ & $66(64.7)$ & $60(61.9)$ & 0.677 \\
\hline Independent in P-ADL & $47(46.5)$ & $48(51.1)$ & 0.527 \\
\hline Impaired hearing, $\mathrm{n}=94$ us 82 & $42(44.7)$ & $34(41.5)$ & 0.667 \\
\hline Impaired vision, $\mathrm{n}=91$ vs 74 & $37(40.7)$ & $27(36.5)$ & 0.584 \\
\hline $\begin{array}{l}\text { Cardiovascular disease } \\
\mathrm{n}=101 \text { vs } 93\end{array}$ & $57(56.4)$ & $53(57.0)$ & 0.938 \\
\hline Dementia & $28(27.5)$ & $36(37.1)$ & 0.145 \\
\hline Depression, $\mathrm{n}=102$ us 95 & $33(32.4)$ & $45(47.4)$ & 0.031 \\
\hline Diabetes, $n=102$ us 95 & $23(22.6)$ & 17 (17.9) & 0.417 \\
\hline Hip fracture, $n=102$ us 96 & $16(15.7)$ & $14(14.6)$ & 0.829 \\
\hline Hypertension, $\mathrm{n}=100$ vs 92 & $40(40.0)$ & $42(45.7)$ & 0.429 \\
\hline Lung diseases, $\mathrm{n}=102$ vs 92 & 19 (18.6) & $14(15.2)$ & 0.528 \\
\hline Osteoporosis, $\mathrm{n}=93$ us 89 & $44(47.3)$ & $51(57.3)$ & 0.177 \\
\hline Wrist fracture, $n=101$ vs 95 & $16(15.8)$ & $23(24.2)$ & 0.142 \\
\hline Stroke, $n=102$ us 93 & $29(28.4)$ & $20(21.5)$ & 0.265 \\
\hline Analgesics & $66(64.7)$ & $50(51.6)$ & 0.060 \\
\hline Antidepressants & $29(28.4)$ & 45 (46.4) & 0.009 \\
\hline Benzodiazepines & $21(20.6)$ & $25(25.8)$ & 0.386 \\
\hline Beta-blockers & $34(33.3)$ & $32(33.0)$ & 0.959 \\
\hline Diuretics & $46(45.1)$ & $33(34.0)$ & 0.110 \\
\hline $\begin{array}{l}\text { Drugs with anticholinergic } \\
\text { properties }\end{array}$ & $20(19.6)$ & $23(23.7)$ & 0.482 \\
\hline Neuroleptics & $13(12.7)$ & $8(8.3)$ & 0.302 \\
\hline Number of drugs, mean \pm SD & $5.8 \pm 3.8$ & $5.9 \pm 3.6$ & 0.862 \\
\hline
\end{tabular}

P-ADL $=$ Personal Activity of Daily Living according to Katz ADL-index; $\mathrm{SD}=$ Standard Deviation

cubitus ulcers $(23.6 \%$ vs $10.7 \%, p=0.059)$.

More assessments of underlying causes of delirium were documented in the nursing records in the intervention ward compared with the control ward $(2.28 \pm 1.25$ vs $0.90 \pm 0.90, p<0.001)$. Similarly, more treatments $(1.69 \pm 1.56$ us $0.56 \pm 0.98, p<0.001)$ for underlying causes of delirium were also documented. Instead, delirious control patients were more often given sedatives (20/48, $41.7 \%$ vs $6 / 39,15.4 \%, p=0.008)$ and opioid drugs on demand $(29 / 47,61.7 \%$ us $12 / 39,30.8 \%$, $p=0.004$ ) than those in the intervention ward.

Intervention patients had shorter total postoperative hospitalization $(28.0 \pm 17.9$ days vs $38.0 \pm 40.6$ days, $p=0.028$ ) than controls, which was also true for intervention patients with postoperative delirium $(31.4 \pm 19.3$ days us $43.6 \pm 42.7$ days, $p=0.032$ ). Delirium in itself was associated with longer hospitalization. Similar pro-
Table 3 - Diagnoses and presenting symptoms for study patients during hospitalization.

\begin{tabular}{|c|c|c|c|}
\hline & $\begin{array}{c}\text { Intervention } \\
\text { group } \\
(\mathbf{n}=102)\end{array}$ & $\underset{\text { Group }}{\text { Control }}$ & \\
\hline Characteristics & n (\%) & n (\%) & p-value \\
\hline Anemia $n=102$ vs 96 & $88(86.3)$ & $79(82.3)$ & 0.441 \\
\hline Constipation & $38(37.3)$ & $47(48.5)$ & 0.110 \\
\hline Decubitus ulcers, $\mathrm{n}=102$ vs 95 & $9(8.8)$ & $21(22.1)$ & 0.010 \\
\hline Depression, $\mathrm{n}=101$ vs 97 & $50(49.5)$ & $53(54.6)$ & 0.470 \\
\hline Diarrhea, $\mathrm{n}=102$ vs 96 & $22(21.6)$ & $26(27.1)$ & 0.365 \\
\hline Heart failure, $n=101$ vs 95 & $6(5.9)$ & $11(11.6)$ & 0.161 \\
\hline \multicolumn{4}{|l|}{ Infections: } \\
\hline Pneumonia & $5(4.9)$ & $3(3.1)$ & 0.722 \\
\hline Urinary infection, $n=102$ vs 96 & $32(31.4)$ & $49(51.0)$ & 0.005 \\
\hline Other infections, $\mathrm{n}=101$ vs 96 & $18(17.8)$ & $17(17.7)$ & 0.983 \\
\hline Sleeping problems & $28(27.5)$ & $44(45.4)$ & 0.009 \\
\hline Myocardial infarction & $2(2.0)$ & $4(4.1)$ & 0.436 \\
\hline Nutritional complications & $25(24.5)$ & $37(38.1)$ & 0.038 \\
\hline Pulmonary embolism & $2(2.0)$ & 0 & 0.498 \\
\hline Stroke & 0 & $1(1.0)$ & 0.485 \\
\hline Stomach ulcers, $\mathrm{n}=101$ vs 97 & $3(3.0)$ & $4(4.1)$ & 0.717 \\
\hline Urinary retention & $16(15.7)$ & 18 (18.6) & 0.591 \\
\hline Falls & $12(11.8)$ & $26(26.8)$ & 0.006 \\
\hline MMSE, mean \pm SD, $n=93$ vs 90 & $17.4 \pm 8.2$ & $15.7 \pm 9.1$ & 0.192 \\
\hline OBS-scale, mean $\pm \mathrm{SD}, \mathrm{n}=94$ us 90 & $10.1 \pm 10.8$ & $12.5 \pm 11.4$ & 0.148 \\
\hline GDS-15, mean $\pm S D, n=81$ vs 68 & $5.2 \pm 3.6$ & $4.5 \pm 3.5$ & 0.271 \\
\hline $\begin{array}{l}\text { Length of hospital stay, } \\
\text { mean } \pm \text { SD }\end{array}$ & $28.0 \pm 17.9$ & $38.0 \pm 40.6$ & 50.028 \\
\hline $\begin{array}{l}\text { Return to own house/apartment } \\
\text { on discharge, } n=64 \text { us } 55\end{array}$ & $48(75.0)$ & $37(67.3)$ & 0.352 \\
\hline
\end{tabular}

MMSE $=$ Mini-Mental State Examination; OBS-scale $=$ Organic Brain Syndrome scale; GDS-15= Geriatric Depression Scale; SD= Standard Deviation.

portions of patients could return to independent living on discharge, despite the shorter ward stay of the intervention group (Table 3). Mortality during hospitalization and at the 4-and 12-month follow-ups did not differ between intervention and control samples (Fig. 1).

When controlling for baseline differences regarding factors known to be associated with delirium $(p<0.15)$ by multivariate linear regression modeling, it was found that there was still a strong association between number of days with postoperative delirium and being treated in the control group (Table 4).

The number of days with postoperative delirium in patients with dementia in the intervention ward was $3.2 \pm 4.1$ days and $12.8 \pm 17.6$ days in the control ward $(p=0.003)$. In addition, 15 patients with dementia in the control ward were still delirious on discharge, in contrast with none from the intervention ward $(p<0.001)$. 
Table 4 - Multivariate linear regression analysis performed to control for baseline differences between intervention and control groups. Dependent variable: number of days with postoperative delirium.

\begin{tabular}{lccc}
\hline Independent variable & $\mathbf{b}$ & Standard Error & $\boldsymbol{p}$-value \\
\hline Delirium preoperatively & 6.06 & 1.59 & $<0.001$ \\
Control group & 4.29 & 1.28 & 0.001 \\
Male sex & 4.20 & 1.45 & 0.004 \\
Depression & 1.56 & 1.38 & 0.262 \\
Dementia & 1.83 & 1.54 & 0.236 \\
Age & 0.18 & 0.10 & 0.080 \\
\hline
\end{tabular}

Adjusted R Square $21.2 \% ; p<0.001$.

Included variables: Age, sex, group, and those variables associated with delirium which differed $(p<0.150)$ at baseline (delirium preoperatively, depression and dementia) between intervention and control groups.

\section{DISCUSSION}

This study shows that patients with postoperative delirium can be treated successfully, resulting in fewer days with postoperative delirium and also in shorter hospitalization. A multi-factorial program with systematic assessment, prevention and treatment of complications causing or prolonging delirium, such as urinary tract infections, hypoxemia, anemia, constipation, falls, decubitus ulcers, and nutritional complications, may have contributed both to fewer days with delirium and to shorter hospitalization.

There were some baseline differences between the intervention and control groups. However, when controlling for baseline differences with multivariate linear regression modeling, it was found that, despite these differences, there was still a strong association between number of days with postoperative delirium and being treated in the control group. The effect of the intervention program seemed to reduce the incidence of delirium already on the first postoperative day (Fig. 2). This may probably be explained by the fact that, when the patients arrived at the intervention ward, they were immediately and systematically assessed to detect, treat and prevent any complications that would cause delirium. Patients with dementia seemed to have benefited particularly from the intervention program. They probably had the lowest threshold for delirium, but delirium is probably often regarded as an unavoidable part of the dementia syndrome. This view, alas, does not encourage any assessment to be made of the underlying preventable and treatable causes of delirium, nor of necessary actions to be taken. This neglect gives rise to unnecessary morbidity and costs. The more widespread use of basic geriatric principles such as this intervention program in surgical wards would no doubt have a great impact, from both humanitarian and economic points of view.

In studies among patients admitted to internal medicine departments, it has been shown that multi-component/multi-factorial interventions resulted in a reduction of the number of episodes of delirium and in a shorter duration of delirium $(18,30,31)$. Among patients with hip fracture, the present multi-factorial intervention program performed by a geriatric team seems to have had better effects than previously published randomized studies $(9$, 16), and the effects seem to be of almost the same magnitude as those reported in a non-randomized intervention study performed according to a similar protocol, in which patients were admitted immediately to a geriatric ward from the emergency room (8). All patients in the present study were admitted to the orthopedic ward from the emergency room and randomized immediately before surgery, to ensure the same preoperative treatment.

One limitation of the present study was that both assessment of psychiatric symptoms and cognitive testing of patients was only carried out on one occasion during hospitalization. According to the assessments carried out by the study nurses, the geriatrician blindly decided whether the patients fulfilled DSM-IV criteria for delirium. $\mathrm{He}$ also decided whether the documentation for each day indicated that the patient was delirious, mainly based on the nurses' records. We have previously shown that nurses detect and document symptoms of delirium better than physicians (32). Analysis of the records was difficult to perform totally blind, but it was difficult or almost impossible to remember to which group the patient belonged, especially since a large proportion of patients in the control group $(n=40)$ were transferred to the geriatric control ward. This means that the comparison was not between geriatric care us orthopedic care, but between an intervention program and conventional care in both the orthopedic and another geriatric ward. The content of the intervention program is in many ways routine treatment for hospitalized patients. This study shows, however, that this is precisely not the case. All parts of this intervention program, which are probably equally important, should be systematically adapted with focus of detection, prevention and treatment of delirium. All assessments and records were analyzed after the study had been finished. Since the staff in the control ward knew about the evaluation of the intervention, but did not know its content, the effect could not be explained by the common study effect alone. Nor could it be explained by increased staffing in the geriatric ward, since there were almost no differences between wards.

The present study shows that delirium is frequent in orthopedic patients (67\%). In 1988, a similar study was presented from the same orthopedic department reporting a $61 \%$ incidence of delirium (3). The high incidence of delirium in the present study may be explained by the high- 
er mean age of patients (82 vs 79 years), and a larger proportion of patients with dementia (32\% vs 15\%), depression (39\% vs $15 \%$ ) and stroke ( $25 \%$ vs $16 \%$ ), which together might have contributed to the high proportion of delirium. In the present study, more patients than previously also had arthroplasty, instead of two hook-pins, which means a more stressful surgical procedure.

Several studies reporting a lower incidence of delirium have often excluded patients with dementia or aphasia, or those with signs of cognitive impairment or delirium on admission, and this inevitably results in a lower incidence of delirium $(5,17,33)$. The present study had several missing cases ( $\mathrm{n}=27$, Fig. 1), which is a disadvantage, but could be explained by the great number of people working in the hospital. It is difficult to organize the whole staff to work for the best interests of the study, since new staff members are being employed all the time. As mentioned earlier, patients who declined or did not participate in the study for any reason, seemed to have been more often admitted from their own apartment/house, had suffered the fracture in the hospital, and were more likely to be men. They seemed to be healthier, and may have reduced the proportion of delirious patients if they had been included in the study.

When analyzing the nursing records, it was found that nurses administered more sedative drugs and analgesics when control patients were delirious. Patients inevitably have some degree of pain after an operation, but if they were worried, restless, in excessive pain or delirious, the reason for their being in this state was not investigated. Symptomatic treatment may have disguised acute symptoms of disease, especially in the control ward, and thus led to a delay in adequate diagnosis and treatment of complications.

The strength of the present study is that the intervention program is applicable both in early postoperative care and in post-acute rehabilitation settings. The main goal is to detect, treat, and prevent the cause of postoperative delirium, since delirium by definition always has an underlying cause. Since the intervention program reduced the number of days with delirium and other postoperative complications, it is also probably applicable to other surgical wards.

\section{CONCLUSIONS}

Today, in industrialized countries, most surgical hospital beds are occupied by old people - an increasing worldwide trend. This study shows that postoperative delirium can be successfully treated by a team applying comprehensive geriatric assessment, management and rehabilitation. It seems that successful intervention programs must include all aspects of good medical and nursing care, and the total effect of the multi-factorial intervention program is without doubt greater than the sum of its separate parts. The intervention program resulted in fewer days with delirium, fewer other complications, and shorter hospital stays. Implementing this intervention program will probably have a great humanitarian and economic impact, and is probably applicable to surgery on old people in general. Therefore, the organization of surgical wards should be reconsidered and adapted to the needs of the oldest and frailest patients.

\section{ACKNOWLEDGEMENTS}

The authors wish to thank all the patients and staff at the Orthopedic and Geriatric Departments at the University Hospital in Umeå. They also wish to thank Börje Hermansson (MD), Eva Elinge (Reg. OT) and Monika Berggren (MD) for fruitful cooperation.

The study was supported by the Vardal Foundation, Joint Committee of the Northern Health Region of Sweden (Visare Norr), JC Kempe Memorial Foundation, Foundation of the Medical Faculty, University of Umeå, County Council of Västerbotten ("Dagmar", "FoU" and "Äldre centrum Västerbotten") and Swedish Research Council, Grant K2005-27VX-15357-01A.

\section{REFERENCES}

1. American Psychiatric Association. Diagnostic and Statistical Manual of Mental Disorders, ed 4. Washington, American Psychiatric Association, 1994.

2. Berggren D, Gustafson Y, Eriksson B, et al. Postoperative confusion after anesthesia in elderly patients with femoral neck fractures. Anesth Analg 1987; 66: 497-504.

3. Gustafson Y, Berggren D, Brännström B, et al. Acute confusional states in elderly patients treated for femoral neck fracture. J Am Geriatr Soc 1988; 36: 525-30.

4. Lundström M, Edlund A, Bucht G, Karlsson S, Gustafson Y. Dementia after delirium in patients with femoral neck fractures. J Am Geriatr Soc 2003; 51: 1002-6.

5. Marcantonio ER, Flacker JM, Michaels M, Resnick NM. Delirium is independently associated with poor functional recovery after hip fracture. J Am Geriatr Soc 2000; 48: 618-24.

6. Kallin K, Jensen J, Lundin-Olsson L, Nyberg L, Gustafson Y. Why the elderly fall in residential care facilities, and suggested remedies. J Fam Pract 2004; 53: 41-52.

7. Gustafson Y, Brännström B, Berggren D, et al. A geriatricanesthesiologic program to reduce acute confusional states in elderly patients treated for femoral neck fractures. J Am Geriatr Soc 1991; 39: 655-62.

8. Lundström M, Edlund A, Lundström G, Gustafson Y. Reorganization of nursing and medical care to reduce the incidence of postoperative delirium and improve rehabilitation outcome in elderly patients treated for femoral neck fractures. Scand J Caring Sci 1999; 13: 193-200.

9. Marcantonio ER, Flacker JM, Wright RJ, Resnick NM. Reducing delirium after hip fracture: a randomized trial. J Am Geriatr Soc 2001; 49: 516-22.

10. McIntosh TK, Bush HL, Yeston NS, et al. Beta-endorphin, cortisol and postoperative delirium: a preliminary report. Psychoneuroendocrinology 1985; 10: 303-13.

11. Flacker JM, Lipsitz LA. Neural mechanisms of delirium: current hypotheses and evolving concepts. J Gerontol A Biol Sci Med Sci 1999; 54: B239-46.

12. Olsson T. Activity in the hypothalamic-pituitary-adrenal axis and delirium. Dement Geriatr Cogn Disord 1999; 10: 345-9.

13. O'Keeffe ST, Devlin JG. Delirium and the dexamethasone suppression test in the elderly. Neuropsychobiology 1994; 30: 153-6. 
14. Sapolsky RM, Pulsinelli WA. Glucocorticoids potentiate ischemic injury to neurons: therapeutic implications. Science 1985; 229 . 1397-400.

15. Milisen K, Foreman MD, Abraham IL, et al. A nurse-led interdisciplinary intervention program for delirium in elderly hip-fracture patients. J Am Geriatr Soc 2001; 49: 523-32.

16. Vidan M, Serra JA, Moreno C, Riquelme G, Ortiz J. Efficacy of a comprehensive geriatric intervention in older patients hospitalized for hip fracture: a randomized, controlled trial. J Am Geriatr Soc 2005; 53: 1476-82.

17. Williams MA, Campbell EB, Raynor WJ, Mlynarczyk SM, Ward SE. Reducing acute confusional states in elderly patients with hip fractures. Res Nurs Health 1985; 8: 329-37.

18. Inouye SK, Bogardus ST, Jr., Charpentier PA, et al. A multicomponent intervention to prevent delirium in hospitalized older patients. N Engl J Med 1999; 340: 669-76.

19. Garden RS. Low-angle fixation in fractures of the femoral neck. J Bone Joint Surg 1961; 43B: 647-63.

20. Sletvold O, Tilvis R, Jonsson A, et al. Geriatric work-up in the Nordic countries. The Nordic approach to comprehensive geriatric assessment. Dan Med Bull 1996; 43: 350-9.

21. Jonsson A, Gustafson Y, Schroll M, et al. Geriatric rehabilitation as an integral part of geriatric medicine in the Nordic countries. Dan Med Bull 2003; 50: 439-45.

22. Folstein MF, Folstein SE, McHugh PR. "Mini-mental state". A practical method for grading the cognitive state of patients for the clinician. J Psychiatr Res 1975; 12: 189-98.

23. Jensen E, Dehlin O, Gustafson L. A comparison between three psychogeriatric rating scales. Int J Geriatr Psychiatry 1993; 8: 215-29.

24. Yesavage JA, Brink TL, Rose TL, et al. Development and vali- dation of a geriatric depression screening scale: a preliminary report. J Psychiatr Res 1982; 17: 37-49.

25. Sheikh J, Yesavage JA. A Geriatric Depression Scale (GDS): recent evidence and development of a shorter version. Clin Gerontol 1986; 5: 165-72.

26. de Craen AJ, Heeren TJ, Gussekloo J. Accuracy of the 15item geriatric depression scale (GDS-15) in a community sample of the oldest old. Int J Geriatr Psychiatry 2003; 18: 63-6.

27. Björkelund KB, Larsson S, Gustafson L, Andersson E. The Organic Brain Syndrome (OBS) scale: a systematic review. Int J Geriatr Psychiatry 2006; 21: 210-22.

28. Eriksson M, Samuelsson E, Gustafson Y, Åberg T, Engström KG. Delirium after coronary bypass surgery evaluated by the organic brain syndrome protocol. Scand Cardiovasc J 2002; 36: 250-5.

29. Katz S, Ford AB, Moskowitz RW, Jackson BA, Jaffe MW. Studies of illness in aged: the Index of ADL: a standardized measure of biological and psychosocial function. J Am Med Ass 1963; 185: 914-9.

30. Lundström M, Edlund A, Karlsson S, Brännström B, Bucht G, Gustafson Y. A multifactorial intervention program reduces the duration of delirium, length of hospitalization, and mortality in delirious patients. J Am Geriatr Soc 2005; 53: 622-8.

31. Pitkala KH, Laurila JV, Strandberg TE, Tilvis RS. Multicomponent geriatric intervention for elderly inpatients with delirium: a randomized, controlled trial. J Gerontol A Biol Sci Med Sci 2006; 61: 176-81.

32. Gustafson Y, Brännström B, Norberg A, Bucht G, Winblad B. Underdiagnosis and poor documentation of acute confusional states in elderly hip fracture patients. J Am Geriatr Soc 1991; 39: 760-5.

33. Sörensen Duppils G, Wikblad K. Acute confusional states in patients undergoing hip surgery: a prospective observation study. Gerontology 2000; 46: 36-43. 